\title{
Para Salvatore Martino. Do mito e retorno
}

Fabio Pierangeli

Estou atormentado por demônios, por infernos. Assim, o poeta siciliano Salvatore Martino, nascido em 1940 nos arredores dos templos agrigentinos, mas já cidadão romano de longas datas, chegou à plena maturidade artística, em 2004, com Livro da renúncia [Libro della cancellazione], editado por Le Torri. No limiar, ele brinca. Não se resguarda do abismo, mas sim retém as faces e os vultos infernais, realiza e segura aquilo que se determina do fogo e da terra, do magma e do caos.

Com as palavras e a sensualidade, com a natureza e os polens na primavera, o poeta atravessou profundamente o caos no espaço e no tempo. Sua linguagem foi e é essa longa, atenta e complexa viagem da experimentação à cristalização sentenciosa da palavra. Do hermetismo da iluminação - através de uma tensão onírica levada à afasia - lembro do complexo e emblemático A fundação de Nínive [La fondazione di Ninive], de 1976, introdução de Ruggero Jacobbi, uma composição babélica de viagens e linguagens, torre e ilha desconhecidas ${ }^{1}$; da reflexão sobre o mito em As cidades possuídas pela lua [Le cittá possedute dalla luna ], de 1978, e deste Livro da renúncia, no qual habitam palavras doadas pela sabedoria, musicalmente palpitantes de amor pela humanidade e pela natureza.

No longo percurso de Martino, os demônios da mente e do corpo, da sensualidade e da poesia, da ambição e da sedução da alma são eficazes condições gnoseológicas por estarem de acordo com a vida, com os seus fascinantes turbilhões contraditórios. O inferno que criamos em união à inveja, à ambição prevaricadora do poder, às escórias, às corrupções e aos falsos deuses, às paixões de plástico do consumismo, aos discursos terminais, ao poderoso esvaziamento das palavras que sofreram abusos, que foram torturadas,

${ }^{1}$ Os outros livros de Salvatore Martino são: Attraverso l'Assiria (Terzo millennio, 1969), Commemorazione dei vivi (Rebellato, 1979), Avanzare di ritorno (Lalli, 1984), La tredicesima fática (Lacaita, 1987), Il guardiano dei cobra (Cultura, 1992). 
divididas, aviltadas, são, ao contrário, os demônios temíveis de que o poeta se afasta.

Neste último livro, no entanto, não há um sinal de lamento, talvez uma busca, uma emoção. Mas, antes de tudo, um desejo de apagar tais escórias e retornar - o máximo possível - a uma relação verdadeira com o mundo. De modo solene, mescla-se à poesia, a fim de não cair na fácil tentação da prédica e do moralismo, como aquele que julga os outros e permite a si próprio o lema: o fim justifica os meios. Não há sinais em Martino de tons sentenciosos, de púlpito ou de discursos pretensiosos.

Os demônios da palavra desapareceram depois de terem deixado páginas memoráveis, pausas, intrigas, labirintos. A partir de As cidades possuidas pela lua a Livro da renúnica, Salvatore Martino inicia outro caminho. Como profetizou seu caro amigo, cara memória aqui evocada, Libero De Libero:

Do meu estilo caótico falavas

Del mio stile caotico parlavi

Obscuro no mar de palavras

Oscuro nel mare di parole

Mas eu devia caminhar por aquela estrada

Ma io dovevo camminare quella strada

Para uma meta de simplicidade

Verso una metà di semplicità

Escutando o magma informe Ascoltando il magma informato

que dentro dormia.

che dentro dormiva.

O magma incandescente lança palavras, quase como a sensualidade. Na primavera, deseja disseminar o seu pólen e acusa os limites, as sufocações, as aventuras erradas, não por tê-las iniciadas, mas para os seus imprevistos êxitos de forças contrárias - talvez com um idêntico peso de razão.

A simplicidade corresponde à sabedoria, à firmeza, a uma leve dor, mas não à resignação, à paralisia, à insensibilidade. Corresponde à palavra fluente e polissêmica, capaz de condensar entre muitos silêncios o destino último da viagem, do aportar, do salino que queima, do azul do mar. O obscuro oceano de palavras é então a tempestade repentina, a taxa paga na fronteira, o certo dos anos. É o ansiar pelo não saber na necessidade poética de comunicar. Intitula-se Acerca do que entendo por poesia [Intorno a quel che intendo per poesia] essa 
admirável lírica, impressa pela doce lembrança de De Libero, e que delineia, silenciosamente, os contornos de uma poética:

Buscar o vulto do enigma

Ricercare il volto dell'enigma

isto é para mim a poesia questo è per me la poesia

a resposta que não podes encontrar la risposta che non puoi trovare

a loucura do espelho la follia dello specchio

a música o silêncio a harmonia la musica il silenzio l'armonia

aquela capacidade de penetrar quella capacità di penetrare

o palácio secreto il palazzo segreto

de preencher a distância das estrelas di colmare il distacco dalle stelle

a alegre inocência da lua. la beata innocenza della luna

Mas como reconquistar o infinito? Seduzindo com beleza os próprios versos, forjando-a, atraindo novamente para os homens os seus olhos distantes, procurando doar um pedaço de céu, de lua remota. A força e o reflexo do enigma na poesia de Salvatore Martino consistem na viagem, na busca nunca adormecida, nos raros momentos de êxtase. E é vivendo na cidade possuída pela lua que se faz ressoar mais uma vez a utopia.

Eis o demônio, o anjo caído, o deus menor:

É o anjo caído a poesia

E' l'angelo caduto la poesia

mas possui o ouvido do Senhor ma possiede l'orecchio del Signore

é o garoto que incendeia è il fanciullo che incendia

a treva infinita

la tenebra infinita

É o guardião da viagem

E' il custode del viaggio

o farol circular

il faro circolare 
aquela fatalidade profetizada quella fatalità presagita

o raio da aurora il lampo dell'aurora

é aquela enganadora estória è quella ingannevole storia

que frivolamente e doce nos possui. che vanamente e dolce ci possiede

Cair do alto, manter-se em equilíbrio no alto, na lama pedir para voltar. Isto prevê o anular-se, o não desdenhar os oxímoros, a feliz, mas não tranqüila contradição do mundo, tendo a coragem, como a fênix, de renascer e de novo morrer.

Martino se anulou no redemoinho das palavras, na experimentação, na criação de mundos e utopias alternativas para depois - jovem amadurecido, desditoso cantor da sorte do mundo e vigoroso cantor de beleza e força - voltar ao mundo da simplicidade, dos territórios encantados e impregnados de paixão pelo humano em que a poesia ainda consente seguir. Desta vez, esclarecendo a magmática palavra, assim como Orfeu sobe, mas ousa descer outra vez ao inferno.

Se for certamente poesia órfica, a cristalina pureza pagã se alinha à tração poética ocidental, que de cristã transmuta em gnóstica dos trovadores até Blake e Rilke. Esses modelos, os demônios, em busca do altar consagrado aos deuses, numa poesia afável, penetrante e, ao mesmo tempo, filosófica, de questões extremas e radicais, escondidas pela aparente facilidade da leitura. A poesia de Martino é insaciável de movimento, da Sicília ao México, por lugares fantásticos e reais. Todos os mares do mundo, locais eleitos e evocados que depois não são mais os mesmos, permanecem pelos versos, ondas sobre areia, rocha. Salvatore Martino é rambler ${ }^{2}$.

Viajando até a paisagem lunar, verossímil e fantástica, com a qual quis empoeirar, leve forma de distância em cidades geográficas distantes e existencialmente próximas, o seu mundo poético em seu último livro editado, o já mencionado As cidades possuídas pela lua. Em perfeito equilíbrio, o múltiplo geográfico e o unitário poético se encontram no estilo seco e essencial, ainda mais lírico. Intimista e brutal com o mundo. Diante do seu lugar

${ }^{2}$ N.do T.: Optou-se por manter o original, porém rambler poderia ser traduzido como 'andarilho'. 
único (os campos romanos fora da cidade, próxima do Soratte declamado pelos poetas), ponto mágico onde converge um conhecimento do mundo, em equilíbrio entre muita amargura e um pequeno aceno de esperança. Dignamente atento à voz interior, em meio a tanta algazarra de idiotices, na qual Martino se sente estranho não por esnobismo, mas eventualmente por amor, ocioso dolorosamente exilado. Nesse exílio, nasce Livro da renúncia. Em um turbilhão poético ressecado, como pelo capim à beira de um barranco, não de renúncia definitiva, mas talvez de derrota resignada. Um velocista, na linha de partida, à espera do tiro que o leve a uma nova existência, mas, enquanto isso, preso e cansado, aflito no espasmo de um nervo tenso, de uma cãibra. A viagem chega a um alto valor poético, em que revive um colóquio debilitado com mestres de vida e poesia, de uma humanidade recente. Tais diálogos são pérolas luminosas, memória de luz, como do túnel de uma brusca noite se entrevê, muito longe, um murmúrio de claridade.

A simplicidade dramática e tensa é um trabalho assíduo de espoliação do banal, estilístico e existencial, um tormento vital e corajoso, uma digna autocensura. Não posso esquecer outro compromisso de Salvatore Martino: o teatro, com uma longa carreira "nas costas" e muitos projetos no futuro. Um traço essencial, felizmente paradoxal, que une as duas experiências artísticas nesse período. Nas prisões, Salvatore está levando, rambler pela Itália, um espetáculo seu sobre o texto de Hugo, O último dia de um condenado à morte [L'ultimo giorno di un condannato a morte $]$, em que cria uma impressionante cumplicidade com os detentos com os quais ensaiou durante a montagem (fui testemunha disso no cárcere romano Regina Coeli).

O teatro, a ação livre do corpo sobre um texto escrito e improvisado - de qualquer modo, sempre diferente - e o cárcere, a noção estrutural e simbólica, além de real, da reclusão, a comoção da caridade para com o homem também são elementos de seu poetizar dessas líricas reunidas (o texto recita exatamente as últimas palavras de um condenado à morte).

Subtrai e aprisiona diante da escuridão das guerras presentes, da incivilidade e barbárie, sofística, dos poderosos das imagens. Renuncia. Renuncia-se. Aprisiona-se, até desaparecer do mundo. E esse nada grita tão alto que nos faz amar e saborear a liberdade. É um belíssimo jogo de paradoxos, é exatamente cárcere, aspiração ao sublime numa sociedade anti-sublime ("se o cárcere obsessivo/ do prazer da harmonia do belo”*), está no centro da meditação da "se il carcere ossessivo/
del piacere dell'armonia
del bello". 
" "la scala dimenticata contro l'albero".

"Chi siamo mi domando? Quale fato ci guida?". sintética lírica epônima do livro. O errar de Martino termina com imagens de graça cotidiana, "a escada esquecida contra a árvore"* , percorrida pelo fogo inextinguível das questões eternas: "Quem somos me pergunto? Qual sorte nos guia?"*

Faz-se sentir o tremor gentil e nobre de uma última aparição de liberdade, a poesia cultivada naquela amizade de verdadeira humanidade com personagens da cultura italiana e estrangeira. Como na lírica epônima, "Livro da renúncia":

Pergunto-me às vezes

Mi chiedo a volte

Quando do rio sobem os vapores quando dal fiume salgono $i$ vapori

e a paisagem assume e il paesaggio assume

as cores tonais do despertar i colori tonali del risveglio

Pergunto-me às vezes mi chiedo a volte

onde se dispersa a vereda marcada dove si disperde il sentiero fissato

se o cárcere obsessivo se il carcere ossessivo

do prazer da harmonia do belo del piacere dell'armonia del bello

pode exorcizar possa esorcizzare

este coágulo de signos questo aggrumo di segni

este habitar dentro da ferida questo abitare dentro la ferita

Quem somos, me pergunto?

Chi siamo mi domando?

Qual sorte nos guia?

Quale fato ci guida?

Tornam-se respostas as perguntas Diventano risposta le domande

Sem nunca sê-lo senza mai esserlo

o que importa? che importa? 
Talvez sejamos aquele fogo imaginário Forse siamo quel fuoco immaginario

A montanha coberta de geleiras la montagna coperta di ghiacciai

A escada esquecida contra a árvore la scala dimenticata contro l'albero

A tormenta e a lua la tormenta e la luna

Somos os depositários do absurdo

Siamo i depositari dell'assurdo

$\mathrm{O}$ viandante emerso da argila il viandante emerso dalle crete

$O$ vazio de um adeus il vuoto di un addio

A areia que purifica os pecados la sabbia che purifica i peccati

$\mathrm{O}$ farol entrevisto de longe il faro intravisto di lontano

Somos a água do rio dos danados Siamo l'acqua del fiume dei dannati

A crônica infinita das lutas la cronaca infinita delle lotte

O arbítrio e o esquecimento l'arbitrio e la dimenticanza

Somos a ilha já desabitada siamo l'isola ormai disabitata

Somos a estrada alada siamo la strada alata

A renúncia la cancellazione

É uma percepção ultimamente positiva da natureza, animada, rica de presença. Cuida-se dela como daquele jardim real e simbólico, labirinto de alma e lugar de escrita. Um outro tema central, além da renúncia e da viagem, acompanha o longuíssimo e premiado itinerário de Salvatore Martino:

\footnotetext{
AQUELA PARTIDA QUE NÃO SABES JOGAR

QUELLA PARTITA CHE NON SAI GIOCARE
} 
Quem sabe? São os deuses

Chissà? Sono gli dèi

a mover o branco e preto

a muovere il bianco e il nero

da nossa partida?

della nostra partita?

ou talvez sejam os homens a sonhar

O forse sono gli uomini a sognare

os movimentos do tabuleiro

i movimenti della scacchiera

esta batalha com a sorte

questa battaglia con la sorte

Os jogadores seguem o movimento

I giocatori inseguono la mossa

inventam aqueles sucessivos

inventano quelle successive

não conhecem o vulto

non conoscono il volto

o frio a eficiência o medo

il freddo l'efficienza la paura

do adversário cego

dell'avversario cieco

do outro lado do quadrado dalla parte opposta del quadrato

Tentam mexer torres bispos

Tentano di spostare torri alfieri

atacar o rei com as peças

di attaccare il re con le pedine

oferecem os flancos aos cavalos prestano il fianco ai cavalli

armam cilada para a rainha tendono l'agguato alla regina

um jogo de pequenas trapaças un gioco di piccoli raggiri

sobre plano fatalmente em duas cores sul piano fatalmente in due colori

Somos as peças de marfim?

Siamo i pezzi d'avorio? 
Ou os homens? Ou os deuses?

O gli uomini? O gli dei?

Todos engaiolados

Tutti ingabbiati

Todos sem saída

tutti senza uscita

Quem sabe se Deus joga a partida?

Chissà se Dio la gioca la partita?

Se distraído nos move com pensamento?

Se distratto ci muove col pensiero?

Ou ele também é movido

$O$ anch'Egli è mosso

por uma peça mais distante?

da una pedina ancora più lontana?

Como se torna estranha esta estória

Come diventa strana questa storia

um cálculo e condiciona un calcolo e condiziona

todo o jogo.

tutto il gioco.

eu o queria encontrar

Io lo vorrei incontrare

este fogo

questo fuoco

este divino conhecimento

questa divina conoscenza

em uma estação de periferia in una stazione di periferia

no hall de um hotel em ruínas nella hall di un albergo fatiscente

em uma louca corrida numa auto-estrada in una folle corsa in autostrada

Mas realmente nasceu

Ma ̀̀ veramente nata

essa tola disputa que vivemos?

questa sciocca contesa che viviamo?

Mestamente abandono

Mestamente abbandono 
" "Io lo vorrei incontrare/ questo fuoco/ questa divina conoscenza/ in una stazione di periferia". os quadrados perfeitos

i quadrati perfetti

onde as fileiras se defrontam

dove le schiere si fronteggiano

em cromática fuga in cromatica fuga

sobre leito fatalmente em duas cores sul letto fatalmente in due colori

o engano l'inganno

o fingimento la finzione

na aurora e do sonho recompostos). nell'alba e dal sogno ricomposti.

Torna-se pungente o pedido de beleza, entendida como um universo em que se podem encontrar os deuses nas variadas formas da natureza e da criatividade humana. Com uma dupla suspeita: que estes não sejam nada mais que o cenário fictício de um evento ou de eventos esperados no futuro, e que talvez tenham alegrado o mundo em tempos de origens douradas ou, ao contrário, que a vida seja tão sutil de razões, tornando-se, na sua totalidade, ilusão.

Todavia o grito, a força, momento central e talvez único do livro, não pára de ecoar, de desejar: "Eu o queria encontrar/ este fogo/ este divino conhecimento/ em uma estação de periferia”* . É necessário abandonar os quadrados fixados, o lugar determinado, exonerar-se do mundo da legislação pactuada, mesmo que nos primeiros momentos isso provoque tristezas e melancolias. A glória mundana provavelmente não alegrará o poeta verdadeiro, sozinho consigo mesmo em meditação. A não ser em oração, secularmente no limiar da aurora, como se fosse o início de todas as coisas em uma posição de escuta originária:

ORAÇÃO NO LIMIAR DA AURORA

PREGHIERA AL LIMITAR DELL'ALBA

Elevou-se a deturpar

Salito a deturpare

com a luz o engano

con la luce l'inganno

astro que pensa a noite

astro che ragiona della notte 
a magia da nostalgia

la magia del rimpianto

aquela solar da renúncia

quella solare della cancellazione

O deus não fala

Il dio non parla

na ambígua morada

nell'ambigua dimora

cada vingança sua é uma esperança

ogni vendetta sua è una speranza

cada minha rebelião um obedecer ogni mia ribellione un obbedire

Réstia de neve liquefeita

Treccia di neve liquefatta

me chames do oráculo perdido mi chiami dall'oracolo perduto

para qual signo me arrastas?

a quale segno mi trascini?

Como desenganar a traição?

Come vanificare il tradimento?

Vazio artifício

Vuoto artificio

que socorres os náufragos

che soccorri i naufraghi

astro gelado das manhãs

astro gelato dei mattini

crucífero da ânsia

crocifero dell'ansia

Com tua manta escondes o medo col tuo mantello celi la paura

na voz segura florescem nella voce sicura fioriscono

todos os juramentos

tutti i giuramenti

Quando poderemos transpor o mito?

Quando potremo sconfinare il mito?

e consagrar ao vento a saliva

e consacrare al vento la saliva 
como uma cantilena de silêncios? come una cantilena di silenzi?

Venha confundir as mentes

Vieni a confondere le menti

demônio branco

dèmone bianco

a rondar os passos da saída.

a circondare i passi dell'uscita.

Eis divino, venha. Na sua própria imagem, ilumine os contrastes: demônio, mas branco, como um anjo. Fogo e gelo em versos memoráveis, entre a audácia da criação, saturação do tédio, consciência do limite. Todos condensados numa fórmula antiguíssima que se coloca agora como pergunta crucial que persegue Martino da aurora de seu caos: mas existem ou nunca existiram esses demônios, e esses deuses, do bem e do mal, adorados e adoradores dos destinos do belo?

Nessas luminosas encarnações, no altar do belo e do justo, convergem os versos do poeta. Eles são o fim da viagem, como sugestivamente escreve Sergio Campailla, que viajou longamente com Martino na estrepitosa introdução do livro: "A sua inconsciente paixão pela derrota se transformou, pela sabedoria de um deus alquimista, numa esplêndida vitória lírica [...] a própria viagem é uma iniciação para o absoluto. Basta, na bagagem, um moeda de ferro, o óbolo para o condutor. E eis o hino a Hermes, a divindade dos segredos, o guia cúmplice”.

A derrota, inicialmente, era mitigada pelo protesto das palavras, agora é catarse e hino, pergunta e invectiva. Os deuses não existiam, eram presenças cobiçadas de sombra escura na potente caótica descrição da primeira viagem em $A$ fundação de Ninive. O respeitável prefaciador, ele também companheiro e mestre de Martino, Ruggiero Jacobbi: "Martino é, literariamente, de família grega: o seu simbolismo se inclina para o alexandrino, o seu surrealismo tem um fundamento clássico. Ele sabe muito bem que ' $\mathrm{O}$ deus não volta', e este é o sentido da história; mas sabe também que não tem resposta”.

"Aqui não se vence mais", continuava o grande crítico, citando um verso emblemático de Nínive e estigmatizando depois como - nesse sentido de morte - Martino encontra uma saída, o caminho da salvação em um novo labirinto, aquele do sexo: “Todo contato carnal é 'condenação', mas ao mesmo tempo con- 
tém o início e o impacto da verdade. Desta passagem sensual, nunca negligenciando a carne e os seus reflexos misteriosos, Martino se encaminha no signo de uma humilde e altiva busca, até encontrá-los, nas últimas coletâneas, aqueles deuses pelo menos em forma de suspeita e de pergunta, paralelamente ao caminho que foi dito anteriormente: da renúncia estilística e do pensamento, da maturidade adquirida. Estes estão dentro do poeta que está em nós e precisam ser redescobertos numa imagem do homem, suprimidos os detritos que ainda pesam, olhando para fora a natureza e as suas incessantes metamorfoses".

Dessa forma, nasce um livro de sabedoria absoluta, poesia leve e filosófica, em equilíbrio admirável, onde o protagonista é o puer em busca da alma. Que precisa se anular do outro mundo, aquele feroz, materialista, da luta e dos desejos perturbados, dos sonhos nunca tidos ou interditos. Sacrificar-se, renunciarse, para obter dentro de si mesmo a volta dos deuses, da poesia verdadeira. É renúncia ou compromisso para o humano? Talvez só Ceronetti e, de modo bem diverso, Testori tenham tentado uma poesia tão agudamente ética, sem limites no moralismo, ensinando a beleza da carne e da alma, como de longe, sem impor, impondo-se respeitavelmente lá onde se encontra o leitor, o outro pronto para colher a mensagem, a cumprir a mesma obra de renúncia.

Com certeza, é um movimento de poucos e Martino o sabe bem, e não consegue se livrar das garras da angústia e da tristeza da sorte do mundo. Assim o renunciar-se permanece um movimento duplo: do mundo e de si mesmo, em busca de uma verdade urgente para comunicar, mas destinada a poucos, aos livres.

$\mathrm{Na}$ lírica em que mais atormentada e urgente se constitui a questão da vida dos deuses, ou seja, da alma carnal, nós o compreendemos, com seus conteúdos irracionais, de luz, sombra e inconsciência, Martino pode concluir, oferecendo-nos a chave da viagem, da próxima viagem poética, o absoluto:

Aconteceram de verdade estas coisas? Accaddero davvero queste cose?

Em qual tempo de nossa memória? In quale tempo della nostra memoria?

São o reflexo de um pensamento Sono il riflesso di un pensiero

de uma ânsia de um fado de um delírio? di un'ansia di un fato di un delirio? 
A nota abandonada

La nota abbandonata

sobre um teclado que não toca mais?

sopra una tastiera che non suona più?

Talvez sejam pesadelos do mar

Forse sono l'incubo del mare

A invisível pegada sobre a areia

l'invisibile orma sulla rena

Aquela água

quell'acqua

Que nos envolve e nos perde che ci avvolge e ci perde

Nos transporta

ci tramanda

Intactos para o absoluto.

intatti all'assoluto

Isso nos envolve, nos perde, nos transporta formidável terna. Na inefável esperança, viajar intactos no último limiar, até o último limiar, o absoluto. No espaço e no tempo.

Tradução

Júlio César Carvalho [UNESA] 


\section{Fabio Pierangeli}

Pesquisador junto à Universidade de Roma “Tor Vergata”, trabalha sobretudo com poesia e narrativa moderna e contemporânea. Tem livros monográficos sobre Pavese, Pasolini, Calvino, Gadda, além de ensaios sobre Leopardi, Verga, Pascoli, Montale, Testori, Morselli e Caproni, ente outros. Preparou para a editora Gribaudo, de Turim, Biografie per immagini: Carlo Emilio Gadda, Luigi Pirandello, e, com Patrizio Barbaro, Italo Calvino e Pier Paolo Pasolini. Publicou ainda Carlo Emilio Gadda. L'indagine dolorosa (1998) e o recente Ultima narrativa italiana (1983-2000). Seus ensaios têm sido publicados em Italianistica, Rivista di Studi Italiani, Studium, Campi Immaginabili, Proteo, Sigma, Tempo Presente, L'Occhiale. É também redator de Sincronie e La Scrittura.

\section{Resumo}

No espaço e no tempo, da poesia ao infinito, Salvatore Martino caminha ao longo da estrada das palavras enigmáticas, criando um fascinante ritual de experiências.

\begin{abstract}
Salvatore Martino treads the pathway of enigmatic words, in space and time, thus creating a fascinating ritual of manifold experiences.
\end{abstract}

\section{Riassunto}

Nello spazio e nel tempo, dalla poesia all'infinito, Salvatore Martino cammina attraverso la strada delle parole enigmatiche, creando un fascinante rituale di esperienze.
Palavras-chave Salvatore Martino mito

poesia

Key words

Salvatore Martino myth poetry

\section{Parole chiave} Salvatore Martino mito

poesia

Recebido em 15/10/2005

Aprovado em 23/12/2005 